\title{
ASEDIOS A LA POÉTICA DE AUTOR
}

Miguel Ángel Malpartida Quispe*

arsnriz@hotmail.com

Universidad Nacional Mayor de San Marcos

Fecha de recepción: mayo de 2018

Fecha de aceptación: diciembre de 2018

Resumen: Este artículo aborda aspectos que se exponen en el marco teórico de la tesis titulada $L a$ autopoética en el proceso creativo de Veloz Niño del Cielo, Veloz Niña del Alba, trabajo presentado para optar el grado de magíster en Escritura Creativa. En el texto, se plantea como objetivo la definición del concepto "poética" a partir de las acepciones que adopta en los estudios literarios (teórica, preceptiva y creativa) hasta arribar al sentido integral que se le atribuirá en la tesis: el develamiento del proceso creativo del autor a partir de una reconstrucción crítica de aquel por parte de un interpretante y/o enmarcada en la voz propia del creador. Para precisar este concepto, se analiza previamente las

* Miguel Ángel Malpartida Quispe estudió Literatura en la Universidad Nacional Mayor de San Marcos (UNMSM), y Educación para el desarrollo, en la Pontificia Universidad Católica del Perú (PUCP). Asimismo, ha cursado la maestría en Escritura Creativa en la UNMSM, y la maestría en Educación, con mención en Políticas y Gestión de la Educación, en la Universidad de San Martín de Porres. Además, ha publicado los poemarios Galería (2002) y Arte de nariz (2007), y artículos de crítica literaria y estudios sobre pedagogía en revistas académicas nacionales e internacionales. Actualmente, se dedica a la docencia en la Universidad Peruana de Ciencias Aplicadas, y prepara la tesis titulada La autopoética en el proceso creativo de Veloz Niño del Cielo, Veloz Niña del Alba. 
convergencias entre la poética, entendida como una actividad, y dos tamices de sentido: la estética posvanguardista y la lírica moderna.

Palabras clave: Poesía, poética, estética posvanguardista, lírica moderna.

\section{SIEGES TO AUTHOR'S POETICS}

Abstract: This article discusses issues that are exposed in the theoretical framework of the thesis entitled The autopoetic in the Creative Process of Veloz Niño del Cielo, Veloz Niña del Alba, work presented to choose the master's degree in Creative Writing. In the text, the objective is the definition of the concept "poetic" based on the meanings it adopts in literary studies (theoretical, prescriptive and creative) until arriving at the integral sense that will be attributed to it in the thesis: the unveiling of the creative process of the author from a critical reconstruction of that one by an interpretant and/or framed in the creator's own voice. To clarify this concept, we first analyze the convergences between poetics, understood as an activity, and two sieves of meaning: the modern poetry and the post-avant-garde aesthetics.

Keywords: Poetry, poetic, post-avant-garde aesthetics, modern poetry.

\section{Introducción}

nte la necesidad de reflexionar sobre mi propio hacer poético en la tesis de la Maestría
en Escritura Creativa de la Universidad Nacional Mayor de San Marcos, surgieron dos modelos de desarrollo. El primero (a) fue, por un momento, el más sencillo de todos: analizar mi propia obra, de forma distanciada, a partir de los conocimientos de teoría e interpretación ganados a partir de mi experiencia como lector de poesía o crítico de literatura, roles a los que mi formación en literatura y docencia me habían acostumbrado. En ese primer momento, considero, no pude apreciar con claridad lo que este trabajo reclamaba de mí, específicamente a partir de la irrupción de un segundo modelo de desarrollo: (b) la descripción y explicación de mi proceso creativo y de los mecanismos de producción textual que puedo activar durante la secuencia de acciones, conscientes o inconscientes, cognitivas o sensoriales, que gradualmente, y de forma imbricada, me permiten elaborar poemas y articularlos en un conjunto, con un destinatario específico. Es a partir de este segundo modelo de desarrollo que decidí partir de la definición del término "poética" e indagar en las acepciones que este ha recibido en los estudios literarios. Mi intención fue construir un 
concepto de poética que me permitiese fundamentar el análisis que desarrollaré acerca de mi propio proceso creativo.

\section{Thes enfoques sobre la poética}

$\mathrm{E}$ l concepto de "poética”, para Tzvetan Todorov, involucra tres sentidos diferenciados: (a) la teoría de la literatura; (b) los códigos o preceptos que son practicados y transmitidos por una escuela literaria, y (c) la elección de un autor entre varias posibilidades literarias en cuanto, por ejemplo, a la temática, la composición y el estilo (Todorov y Ducrot, 1975).

Como se aprecia, el primero de sus significados es el que ha adquirido de modo tradicional a partir del tratado Poética, de Aristóteles, hasta arribar a las propuestas estructuralistas de una poética textual dominante. Ello abarca la reflexión teórica sobre la literatura, sus concepciones, las características que la distinguen de otras prácticas y la forma en que esta se comprende, no sin que el término haya transitado por una perspectiva romántica que se enfocó en el creador y devino en el biografismo del siglo XIX contra el que se enfrentaron los estructuralistas (Rivas, 2005).

No obstante, existe una concepción que históricamente transita paralela a esta, y que respeta el sentido doble que le imprimió Aristóteles: aquel que establece el aspecto preceptivo de la poética. Este refiere a los aspectos de estilo que distinguen a un género o movimiento literario específico, y que, generalizados a partir de las obras existentes, configuran aspectos formales o temáticos en común y los convierten en preceptos estéticos, los cuales identifican, difunden y contribuyen a la comprensión de tales prácticas por parte de los lectores y de los propios autores.

De acuerdo con ello, es posible encontrar, por ejemplo, una poética del Renacimiento y del Siglo de Oro, en la que el creador alcanzaba la originalidad a través de la imitación sin dejar de sentir su obra como una creación propia. Es decir, el escribir literatura se entendía como una adaptación del estilo y de la sensibilidad del autor, su proceso creativo, a la poética preceptiva de su horizonte de lecturas. Como se observa, en esta acepción de poética, la mímesis era considerada como el núcleo dinámico de la creación y el concepto de poética involucraba un saber institucionalizado y preceptivo (García de la Torre, 1983): 
Era humanista en el Renacimiento quien dominaba los studia humaninatis. Una de las materias en ellos comprendida era la Poética, pero su objeto difería esencialmente de lo que hoy se entiende por ese término. En las Scholae medievales, el gramático enseñaba Gramática y Poética unidas, pero desde el siglo XIV comenzaron a dividirse sus parcelas, restringiendo la Poética al estudio- lectura y entendimiento- de los poetas latinos clásicos y a la práctica de la escritura imitándolos. (...) En la base, por tanto, de la creación literaria humanista, ya se trate de obras de ficción, ya de literatura didáctica, está el ejercicio de la imitación, posteriormente convertido en doctrina que informa todas las obras renacentistas. De ello hicieron eco las poéticas del Siglo de Oro cuya temática gira en torno a la normativa de la imitación. (...)

[En este contexto] el auténtico maestro era el que consentía con los autores imitados pero a la vez sentía como propio su producto. El proceso creativo, por tanto, partía de la experiencia íntima, acudía a la memoria de sus lecturas clásicas o modernas, y en último término expresaba el sentimiento de su experiencia ayudándose de esas lecturas. Describir las deudas intelectuales de un escritor era descubrir su secreto, su cultura, pero en modo alguno podía entenderse como falta de originalidad. (pp. 79-80)

Por otro lado, alejado de la poética de una escuela y más cercano a la de un tipo o género literario, Gianni Rodari (2004), escritor y pedagogo, describió también el vínculo preceptivo entre la poética personal de un autor y, específicamente, la poética de la literatura infantil. Planteó su poética preceptiva en función del tipo de lector o del tipo de sensibilidad con la que los autores adscritos a este tipo de literatura pretenden dialogar:

Igualmente, el que escribe para los niños acepta unos límites, escoge una clave y ha de utilizar esa clave; de su propia experiencia escogerá lo que no parezca a la experiencia infantil demasiado extraño o lejano. Si escribe sobre temas de ciencias, evitará el lenguaje familiar a los científicos, etc. Si escribe historias fantásticas deberá controlar su fantasía para que sus imágenes no resulten incomprensibles, como si fueran palabras desconocidas (...) 
Los niños no creen en un mundo separado del nuestro, en un ghetto o bajo una campana de cristal (...) No hay ni un solo problema del presente al que los niños no sean sensibles, aunque a veces parezcan distraídos. Los libros para los niños de nuestro siglo no pueden aparentar que el siglo no existe y que no transcurre, tumultuoso, a nuestro entorno. Un buen libro para los niños de hoy debe ser un libro que sintonice con el calendario y con sus problemas. (párr. 23)

Como se aprecia, la poética de la literatura infantil planteada por Rodari (1987) descubre al creador la necesidad de adaptarse a un tipo de lector y, por ende, de sensibilidad, sin subestimar su capacidad de comprender el mundo. Con ello, el autor generaliza una preceptiva que se opone, reacciona, ante otros horizontes de lectura y producción de literatura infantil que se encuentran incluso vigentes, los cuales la instrumentalizan hasta el punto de reducirla a su finalidad pedagógica, la cual se puede disfrazar bajo un halo de ludismo y ensońación, tal como denunció, en su momento, Hazard (1949):

(...) Simulemos edificar los mágicos castillos que los encantan, pero a nuestro modo, pues la auténtica sabiduría es patrimonio nuestro. En sus palacios pondremos aulas, muy bien disimuladas; en sus jardines sembraremos legumbres, que los niños creerán flores. En los recodos de las avenidas aparecerán el orden, la prudencia y la Historia Natural, con la Física y la Química; simulando seguir el hilo de las antiguas consejas, les narraremos cuentos científicos. Como son unos ingenuos, apenas lo notarán; y creyendo divertirse, desde la mañana hasta la noche, aprenderán, en realidad, cosas útiles. (pp. 13-14)

Como se observa en la poética del Renacimiento y el Siglo de Oro, descrita por García de la Torre (1983), y en la que propone Rodari (1987) con respecto a la literatura infantil, la poética sintetiza los aspectos formales o temáticos que caracterizan a un movimiento o escuela, y a un tipo de literatura, respectivamente, y establecen, con el transcurrir del tiempo, aspectos estilísticos preceptivos tan necesarios para que un autor reconozca su tradición 
escritural, y escriba en sus linderos o experimente en sus márgenes. De acuerdo con ello, esta acepción de poética, la preceptiva, se manifiesta como un fenómeno indesligable del proceso creativo, en la medida en que este se configura como un evento de síntesis entre lo que exige la tradición (el saber hacer) y lo que corresponde a la voluntad constructiva del autor (el hacer en sí mismo, es decir, la disposición de los elementos).

Finalmente, la tercera acepción de poética, sintetizada por Todorov, se enfoca directamente en el autor, aunque involucra los otros dos aspectos (realtivos al texto y la tradición). Esta acepción resulta de particular importancia para mi trabajo. La poética, entendida como el proceso creativo de un autor específico y su devenir en la obra que va construyendo, configura, según las fuentes revisadas, el significado más elusivo. La mayoría de veces los críticos reconstructores de las poéticas de autores específicos no se decantan por definir el concepto de poética o lo dan por sobreentendido (Eco, 2000 Levin, 2006) o dejan al lector la labor de su dilucidación (Melchiori, 1994). Otro tanto ocurre con los autores, quienes describen su poética apelando a que el lector comprenda de modo tácito el significado de su procedimiento de autorreflexión (Watanabe, 1999). En las últimas décadas, no obstante, las reflexiones sobre las denominadas poéticas de autor, autopoéticas o poéticas específicas han cobrado fuerza (Rubio, 1990; Badía, 2017).

\subsection{Poética enfocada en el autor}

A partir de estas tres acepciones, antes de proponer un concepto específico, considero conveniente tamizar la tercera noción de poética, e inscribirla en el marco de dos ámbitos que configuran un espacio de reflexión en constante debate: la estética posvanguardista y la lírica moderna. Realizo ello, debido a que la poética, entendida como proceso creativo o mecanismo de producción, involucra (a) la elaboración de un producto estético, una obra de arte, y (b) una disposición creativa en cuanto al uso del lenguaje. Con ello, procuro establecer el concepto en función de su naturaleza y su especificidad.

\subsubsection{Pautas de reconocimiento}

Poética y estética. La indagación sobre el concepto de poética se sujeta a las discusiones teóricas en torno a la estética, en su devenir continuo entre las nociones de (a) percepción y (b) teoría del arte. En el terreno de la estética, específicamente la de posvanguardia, la poética 
puede ser comprendida en función de su manifestación de texto literario, el cual configura un producto artístico, resultado de un mecanismo de producción en el cual intervienen diversos factores creativos y se buscan variados efectos estéticos. En las líneas que siguen, se establecen cuatro perspectivas que esclarecen aspectos de la poética en relación con la estética posvanguardista.

La poética, experiencia develadora del proceso creativo. Wajcman (2001) precisó que el objeto artístico es un artefacto estético que se muestra ante la mirada del otro, el espectador, pero que, esencialmente a partir de las experiencias de la vanguardia, es capaz y tiene la finalidad de transformar la mirada de quien observa a través de la puesta en acto de lo que quiere representar:

Hablar de "obra de arte" es concebir primero un producto, un objeto en tanto producto de una actividad, de un savoir-faire, de una mano, de un pensamiento, de una conciencia, de una tradición, etc. Se trata, digamos, de lo que habitualmente se concibe como "obra de arte". Lo que yo quisiera poner en primer plano es otro aspecto: que este producto realiza por sí mismo una obra, actúa, tiene algún efecto, digamos, sobre los sujetos. La obra del arte es esa especie de oxímoron material multiplicado que funda el arte: un objeto que realiza un acto, un producto que es una causa. (pp. 34-35)

Entendido de este modo, la obra de arte no es un objeto que se observe y se clasifique como tal, sino que traspone su naturaleza material hasta configurar una experiencia artística en sí misma, que se instala en la visión del espectador de forma cuestionadora. A través de esta personalización de la obra, Wajcman (2001) expresó que las obras no son objetos sobre los cuales teorizar, sino actos-objeto que implican en sí mismos cuestionamientos (cambios de mirada) como resultado de la convergencia del autor y del receptor, implicados en la obra misma y no como elementos externos.

De acuerdo con este enfoque centrado en la obra de arte, en la mismidad de lo que Wajcman (2001) denomina "obras-del-arte", la teoría, que antes se preocupaba por establecer regularidad entre los objetos artísticos con el fin de sujetarlos a un modelo explicativo, se relativiza y se convierte en "teoría de las obras" y deja de ser "teoría del arte" en un sentido universal. Esto quiere decir que, en su intransferible particularidad, cada obra de arte exige, 
por sí misma, una teoría que la describa y la explique. En estos términos, el arte no necesita de un mediador (teórico o crítico) para existir, sino de un "mirador" implicado en lo que ve, y que se arriesgue a cambiar su visión del mundo a través de dicha observación.

Esta perspectiva implica, además, que el creador, a partir de la modernidad, asuma su proceso productivo como parte de la finalidad potencial del arte: el "hacer ver" al espectador más allá de lo evidente, de lo representativo y de lo mimético: "El arte no reproduce lo visible, vuelve visible" (p. 37). De acuerdo con su propuesta, Wajcman (2001) coloca en relieve la pintura como un arte "creador de mirada", que, en su forma material y creativa, devela y habitúa la mirada de su espectador a un tipo de representación que, luego, en la realidad, influye de tal forma en su visión del mundo que termina por configurar una especie de "anteojo" que reinventa su visión y da forma a sus percepciones, ideas, creencias y experiencias.

En este sentido, la poética, entendida desde el lado de la estética, se despoja de su aspecto teorizante y se abre a la posibilidad de reflexionar filosóficamente sobre el arte como un fenómeno capaz de develar su propio sentido. Para ello, se parte de la idea de que toda obra de arte (literaria, plástica, musical, cinematográfica o de otros códigos) carece de "una" teoría que la explique necesariamente; más bien, al ser un producto único, contiene en sí misma una gramática propia que se debe develar, y que procede de la experiencia estéticovital de su creador como elemento indesligable de su producción.

Al respecto, cabe mencionar, a modo de ejemplo, los estudios fenomenológicos realizados por Gastón Bachelard (1997) en pos de explorar las poéticas de la ensoñación y del espacio en diversos corpus textuales a partir de las imágenes que identifican ambos conceptos. En su propuesta, este autor desarrolla una lectura de la imagen poética como un fenómeno que se manifiesta ante la subjetividad del lector, compone directrices en las obras de los autores, y genera dinámicas que pueden rastrearse hasta su proceso creativo:

Según los principios de la fenomenología, se intentaba sacar a plena luz la toma de conciencia de un individuo maravillado por las imágenes poéticas. (...) $\mathrm{Al}$ obligarnos a cumplir un regreso sistemático sobre nosotros mismos y un esfuerzo de claridad en la toma de conciencia, a propósito de una imagen dada por un poeta, el método fenomenológico nos lleva a intentar la comunicación con la conciencia creante del poeta. La imagen poética nueva — ¡una simple 
imagen! - llega a ser de esta manera, sencillamente, un origen absoluto, un origen de conciencia. (pp. 10-11)

Como lo evidencia la cita, Bachelard (1997), al plantear su idea de poética, se inclina explícitamente hacia la tendencia perceptiva de la estética. Su propuesta se aleja de la poética textual, y "construye" o más bien "devela" una teoría de la obra de arte fundamentada en la ampliación de la conciencia individual. En su acercamiento, considera, como importante elemento de análisis, las experiencias estético-vitales del productor y del interpretante: “Y qué gloria de lectura si logro vivir, ayudado por el poeta, la intencionalidad poética!" (p. 14). De acuerdo con ello, al plantear su concepto de poética, más allá del evidente esencialismo de su propuesta, a Bachelard le interesa incluir el tipo de experiencias que la teoría institucionalizada de base estructuralista elude en su modo crítico. Nos referimos a las experiencias estético-vitales, que son entendidas como un fenómeno que imbrica ambas dimensiones en el sentido que el interpretante reconstruye, y cuya inclusión en el análisis traza un puente que reintegra los aspectos emotivo-volitivos del autor en la exégesis de su obra.

La poética, autorreconocimiento del creador. Sin embargo, al transitar el arte las vanguardias y posvanguardias, la experimentación de los artistas y los constantes cambios de paradigmas hacen que la estética, entendida ahora como teoría del arte, se convierta en una especie de compensación, más que para los críticos, para los creadores, en el desarrollo de su proceso creativo. Al respecto, Groys (2016) mencionó que los artistas contemporáneos:

(...) necesitan de la teoría para explicar lo que están haciendo, no a los otros, sino a sí mismos. En este sentido, no están solos. Hoy cada persona se hace constantemente estas dos preguntas: ¿qué hay que hacer? y, otra más importante, ¿`cómo me explico lo que ya estoy haciendo? La urgencia de estas preguntas surge del colapso de la tradición que experimentamos hoy en día. (...)

Para empezar a producir arte, uno necesita una teoría que explique qué es el arte. Tal teoría hace posible que los artistas universalicen, globalicen su arte. El recurso a la teoría los libera de sus identidades culturales, del peligro de que 
su arte sea percibido solo como una curiosidad local. Esta es la razón principal de la proliferación de la teoría en nuestro mundo globalizado. Aquí, la teoría -el discurso teórico y explicativo — precede al arte en lugar de seguirlo. (pp. 34-35)

Planteada desde esta perspectiva, la poética puede ser entendida como un proceso de autoreconocimiento del propio autor en cuanto a sus propias elecciones estilísticas, técnicas o temáticas en función de la proyección de su artefacto artístico en la mirada del espectador. Esta elaboración, que supone la autoconciencia del autor y su conocimiento de la tradición, se muestra como un proceso que debe ser mostrado por el propio artista, el cual requiere una explicación personal de su mecanismo de producción a fin de potenciar sus efectos estéticos, la percepción de su arte. Cabe agregar que los estudios en Escritura Creativa han institucionalizado esta búsqueda. Para Groys (2015), se ha operado un cambio que ha transformado la estética en poética, y precisamente, en autopoética:

Esto implica que el arte contemporáneo debe ser analizado, no en términos estéticos, sino en términos de poética. No desde la perspectiva del consumidor de arte, sino desde la del productor. De hecho, la tradición que piensa al arte como poiesis o techné es más extensa que la que lo piensa como aisthesis o en términos de hermenéutica. El deslizamiento desde una noción poética y técnica del arte hacia un análisis estético o hermenéutico fue relativamente reciente, y ahora llegó el momento de revertir ese cambio de perspectiva. De hecho, esta inversión ya empezó con la vanguardia histórica, con artistas como Wassily Kandinsky, Kazimir Malevich, Hugo Ball o Marcel Duchamp, que crearon narrativas publicas en las que actuaron como personas públicas colocando al mismo nivel artículos periodísticos, docencia, escritura, performance y producción visual. Vistas y juzgadas desde una perspectiva estética, sus obras se interpretaron, fundamentalmente, como una reacción artística a la revolución industrial y a la agitación política de la época. Claro que esta interpretación es legítima. $\mathrm{Al}$ mismo tiempo, parece incluso más legítimo pensar estas prácticas artísticas como transformaciones radicales desde la estética a la poética, más 
específicamente hacia la autopoética, hacia la producción del propio Yo público. (pp. 15-16)

La poética, práctica social en el tiempo. Desde otra vertiente, Eagleton (2006) se encarga de vincular la estética, una práctica cultural, con los procesos de transformación de la estructura social y productiva de las sociedades modernas. Este autor defiende la idea de que lo estético es un terreno de lucha ideológica. Al respecto, mencionó lo siguiente:

La construcción de la noción moderna de artefacto estético no se puede por tanto desligar de la construcción de las formas ideológicas dominantes de la sociedad de clases moderna, así como, en realidad, de toda una nueva forma de subjetividad humana apropiada a este orden social. Es este fenómeno - $y$ no tanto el hecho de que los hombres y las mujeres descubrieran súbitamente el supremo valor que supone el hecho de pintar o escribir poesía- el que provoca que lo estético desempeñe una función tan singular dentro de la herencia intelectual de nuestro presente. Mi tesis, sin embargo, es que lo estético, entendido en cierto modo, también proporciona un poderoso e inusual desafío y una alternativa a estas formas ideológicas dominantes, razón por la cual se revela como un fenómeno eminentemente contradictorio. (pp. 53-54)

La propuesta de Eagleton (2006), según nuestra perspectiva, coloca a la poética en la situación de ubicarse entre los factores sociales de su determinación. De este modo, los cambios en la producción artística y la experiencia estética resultante se sujetan al devenir de la lucha de clases, y, evidencian, en su conocimiento por parte de los creadores y del público, las posturas de los grupos de poder hegemónicos o en ascenso. Un ejemplo de esta correspondencia es el cambio de enfoque sobre la niñez en el ascenso de la burguesía y su impacto en el surgimiento de la literatura infantil (López Tamés, 1990).

Por otro lado, Rancière (2011) abarca otro aspecto importante de la discusión sobre la obra de arte como producto estético. Este autor menciona que, en la historia del arte, se ha transitado de un régimen representativo, dominado por el procedimiento de la mímesis, 
hacia un régimen estético del arte, básicamente un modo de identificar el arte, en el cual existe "una relación sin mediaciones entre el cálculo de la obra y el puro afecto sensible" (p. 16-17), que coloca en diálogo la poiesis y la aisthesis durante el proceso creativo. De acuerdo con ello, para el autor, se comprueba la existencia de "un régimen estético donde se diluye la distinción entre las cosas que pertenecen al arte y aquellas que pertenecen a la vida cotidiana” (p. 14).

La resonancia de esta perspectiva en terrenos de la poética se expresa en la posibilidad de plantear la naturaleza indesligable, en el acto creativo, de los conocimientos técnicos, el saber hacer, y los aspectos subjetivos de la creación (las experiencias concretas y estéticas a partir de las cuales el creador elabora su producto). Esto quiere decir que, para determinar una poética, es necesario cercarla desde estos dos ámbitos sin que uno se imponga sobre otro, sino que se muestre el involucramiento que existe entre estos.

La poética, develadora del estilo creativo. Ya embarcados en terrenos del acto creativo, Agamben (2016) lo definió a partir de la inserción de los conceptos aristotélicos de potencia y acto en la propuesta de Deleuze sobre el arte como resistencia. De acuerdo con ello, explicó que el acto de creación es un campo de fuerzas en tensión entre la potencia y la impotencia del acto creativo, generados por la capacidad de resistir a una influencia o presión. Es esta dinámica entre la posibilidad de desarrollar la potencia (la posesión de una habilidad o una técnica) y la impotencia (ese "algo" que se opone a la expresión y que tiende a la no realización) la que permite al artista construir su producto artístico. En la medida de que ambas fuerzas son definidas en función de la posibilidad de su no ejercicio, de su suspensión, cabe desentrañar qué es aquello que mueve al artista a salir de esta indefinición:

El hombre puede tener control sobre su potencia y tener acceso a ella sólo a través de su impotencia; pero — precisamente por eso- no posee, en realidad, control sobre la potencia; y ser poeta significa ser presa de su propia impotencia. (p. 40)

En consecuencia, el acto poético involucra en sí mismo la propia potencia de no ser realizado. Es decir, el artista puede desarrollar una habilidad, una potencia, al no realizar el acto creativo. Esto implica definir tres elementos: (a) la capacidad, que supone el abandono de la imposibilidad de crear, o sea, la posibilidad de hacerlo; (b) el talento, o la 
tendencia ineludible a realizar la actividad, y (c) la maestría, que "conserva y ejercita en el acto no su potencia de tocar, sino la de no tocar" (p. 40), es decir, de resistirse al acto, de entender su posibilidad de no hacerlo, su contingencia. De este modo, se aleja de la idea de maestría como perfección, sino que reconoce esta característica en los artistas que, gracias a un momento de crítica hacia su propio arte (la resistencia), muestran en su obra la marca de la imperfección:

En la perspectiva que nos interesa, la aparente contradicción entre hábito y mano no es un defecto, sino que expresa perfectamente la doble estructura de todo auténtico proceso creativo, íntima y emblemáticamente suspendido entre dos impulsos contradictorios: impulso y resistencia, inspiración y crítica. (p. 41)

Es en este espacio de crítica que el artista resiste el acto creativo y, creo yo, reconoce que, en todos los casos, sus medios de expresión son limitados, lo cual impide que cumpla su deseo de volcar toda la capacidad (hábito o técnica) y el talento en el producto artístico. Agamben (2016) le confiere a este estadío el nombre de inoperosidad. Esta es definida como una praxis o potencia especial que acompaña al desarrollo de la obra y que consiste en la contemplación de la propia potencia de actuar. Esta etapa de la creación, este vértigo, configura una conciencia del propio arte, de modo autorreferencial, lo cual es esencia del arte.

Agamben (2016), incluso, plantea una "poética de la inoperosidad", es decir, el procedimiento mediante el cual el creador, durante el acto creativo, se contempla a sí mismo como operador de su lengua (social), es decir, como apropiador de su propio lenguaje (estilo). Esto le imprime a cada una de sus obras, según mi percepción, un "arte poética implícita": "Este resto inoperoso de potencia es lo que hace posible el pensamiento del pensamiento, la pintura de la pintura, la poesía de la poesía” (p. 45).

Es decir, el arte que hay en cada obra es una evidencia de lo que pudo hacer el artista y de lo que hizo finalmente, de sus elecciones conscientes o inconscientes entre un conjunto de variables (repertorio), que configuran las características de su propio hacer, en otros términos, su poética. Pero, también, casi de modo sinecdótico, representa el devenir de la poesía como práctica generalizada, es decir, el espacio de la lírica: “¿Qué es la poesía, sino 
una operación en el lenguaje que desactiva y vuelve inoperosas las funciones comunicativas e informativas para abrirlas a un nuevo, posible uso?" (p. 49).

$\mathrm{Al}$ referir al acto creativo, es ineludible indicar la relación que existe entre la práctica general y el estilo del autor. Al respecto, sobre la conformación del estilo en el ámbito cambiante del lenguaje, a partir de la doble alegoría del "misterio-fuego" que es atisbado (ganado y perdido, al mismo tiempo, en un intento de recuperación) por la "historia-relato", es decir, la literatura, Agamben (2016) señaló lo siguiente sobre los polos de la creatividad verbal (estilo y manera):

La lengua del escritor — como el gesto del artista — es un campo de tensiones polares, cuyos extremos son el estilo y la manera. "El hábito del arte" es el estilo, la posesión perfecta de sus propios medios, donde la ausencia del fuego es asumida de forma perentoria, porque todo está en la obra y nada puede faltarle. No hay, no ha habido nunca misterio, porque siempre ha estado expuesto, aquí, ahora y por siempre. Pero este gesto imperioso ocurre, de vez en cuando, como un temblor, algo como una íntima vacilación donde el estilo escapa bruscamente, los colores se desvanecen, las palabras balbucean, la materia se vuelve grumosa y se desborda. Este temblor es la manera que, en la deposición del hábito, muestra una vez más la ausencia y el exceso de fuego. $\mathrm{Y}$ en todo verdadero escritor, en todo artista, existe siempre una manera que toma distancia del estilo, un estilo que se desapropia en la manera. (p. 16)

A partir del planteamiento de estas cuatro perspectivas sobre el producto estético, aplicadas al concepto de poética de autor, se propone las siguientes ideas guía con respecto a los componentes de esta acepción de poética:

- Objeto artístico y receptor: El proceso creativo del escritor está encaminado, conscientemente, a la producción de una obra de arte, entendida como un actoobjeto, como una experiencia en sí misma que genera el cambio de visión de mundo del lector a partir de su mismidad. Esto implica tres sentidos: (a) la obra no necesita de una explicación teórica para existir, sino de un lector implicado en 
la experiencia; (b) la obra no apela a la mímesis, sino que devela, vuelve visible su propia realidad, que afecta a la del lector; (c) cada obra alberga en sí un modo de ser interpretada, una especie de gramática de sí misma.

- Creador: Sin embargo, el escritor, en el panorama del arte contemporáneo, requiere darse a sí mismo una explicación teórica de su propio acto de creación con la finalidad de diferenciarse frente a su lector. Esta intención se formula como un autoreconocimiento de su proceso creativo en función de su proyección en la mirada del otro.

- Sociedad: La poética evidencia necesariamente el trasfondo de lucha ideológica en el panorama social y estético del cual procede la obra. De acuerdo con ello, el proceso creativo también evidencia los cambios de percepción acerca del objeto artístico y de la forma de hacer arte, que varía de acuerdo con los intereses de grupos dominantes y la resistencia que existe frente a estos.

- Acto creativo: El acto de creación configura una tensión que se produce entre el saber hacer (el hábito o la técnica), la disposición para hacerlo (la voluntad) y las elecciones particulares del escritor (estilo).

- Poética: Establecer una poética, entendida como una forma de explicar el propio arte, implica explicar la vinculación, en el acto creativo, de los aspectos técnicos y subjetivos de la creación sin desmerecer ninguno de estos.

Poética y lírica. Tradicionalmente, la lírica ha sido comprendida como un género literario, en cuanto a su punto de enunciación y mundo representado, con respecto a los géneros dramático y épico-narrativo. De este modo, Berinstain (1995) recoge la idea de que el género lírico se caracteriza por la preminencia de "una actitud típica que corresponde a la enunciación (reservada al poeta) que manifiesta la intimidad del sujeto de la enunciación, que es la autoexpresión de un estado de ánimo, de 'una emoción en que lo objetivo y lo subjetivo se han compenetrado', de un yo, de una subjetividad anímica” (p. 241). Cabe añadir que esta focalización en el sujeto subordina a las otras intenciones, descriptivas o narrativas, y las convierte, siguiendo las propuestas de Barthes, en funciones connotativas que participan en la conformación de imágenes a través de figuras retóricas como la metáfora, la alegoría, la antítesis, etc. (Berinstain, 1995). Sin embargo, este encasillamiento ha sido discutivo a partir de propuestas que han cuestionado sus criterios de definición, 
por ejemplo, (a) el sujeto lírico de su enunciación y (b) el proceso de mímesis que guía su disposición de recursos expresivos.

Con respecto al primer criterio, Combe (1999) ha precisado que, en el panorama histórico de los estudios literarios, específicamente a partir de las propuestas estéticas y filosóficas del Romanticismo alemán, la lírica ha sido comprendida como un género discursivo anclado en la subjetividad del hablante, en su individualidad como sujeto de enunciación y mundo representado. Ello, expone el autor, ha generado una serie de presupuestos que han tenido escasa discusión y que le han restado amplitud al término y a su comprensión a partir de su producto, el poema lírico. Estos presupuestos son los siguientes: (a) el sujeto lírico expresa al poeta en su autenticidad; (b) la poesía lírica se expresa en nombre del autor mismo; (c) la poesía lírica excluye a la ficción; (d) el exégeta puede leer el poema como la expresión del contenido del "yo creador"; (e) al ser un sujeto real, el sujeto lírico también es un sujeto ético; por tanto, enjuiciable a partir de su obra y viceversa.

Estos presupuestos han sido superados por reflexiones posteriores, las cuales proponen, con respecto a la enunciación, un panorama menos restrictivo. Las nuevas líneas de estudio de la lírica la definen como "un tipo de discurso centrado esencialmente en torno a una determinación enunciativa" (Cabo, 1999, p. 10), lo cual lo convierte en un discurso tendiente a la metapoética, y con una gran apertura para incluir, en su tradición, prácticas escriturales nuevas, y para adaptarse a las nuevas sensibilidades que problematizan identidades y nuevos medios expresivos (Cabo, 1999).

Por otro lado, con respecto al segundo criterio, el cual abarca el proceso de mímesis de la lírica, Merquior (1999) expone, ya desde 1965, sus cuestionamientos a que la lírica se asocie, en desventaja con respecto a los demás géneros, con la mímesis aristotélica. El autor propone que el texto lírico, el poema, se rige más bien por la mímesis interna, que tiene la capacidad de sintetizar conceptos universales mediante la figuración de seres singulares, lo cual la convierte en el "modus operandi" de la literatura en general. Es así que, de ser solamente la representación de la interioridad del poeta, específicamente de sus estados de ánimo (por tanto, sin trascendencia a la universalidad), la lírica pasa a convertirse en la dinámica general del proceso creativo y de la disposición que identifica a la literatura misma, incluso. Este autor, específicamente sobre el producto de la lírica, en su sentido ampliado, menciona lo siguiente: 
El poema es una especie de mensaje verbal fuertemente regido, en cuanto al funcionamiento del lenguaje, por la proyección del principio de equivalencia del plano de la selección de las palabras sobre el plano de su secuencia en la frase. Este mensaje consiste en la imitación de estados de ánimo (stasis), y tiene por finalidad la transmisión indirecta, por medio de estímulos no puramente intelectuales, de un conocimiento especial acerca de aspectos de la existencia considerados de interés permanente para la humanidad. (p. 95)

Finalmente, una perspectiva que amplía aún más el concepto de lírica es la que sostiene Reisz (1989). Para esta autora, la poesía como actividad que supera al encasillamiento del género, se configura a partir de características que la emparentan con otras experiencias estéticas e incluso códigos diferentes:

La poesía parece caracterizarse, respecto de otras formas literarias, por una mayor proximidad a otras artes no-verbales como la música y las artes plásticas. (...) [en cuanto a que manifiesta] la capacidad — siempre disponible pero no siempre explotada - de poner de relieve el lado concreto y sensorial de los signos lingüísticos para obtener con ellos efectos acústicos y/o visuales portadores de informaciones adicionales que se superponen a las propiamente lingüísticas. (p. 52)

Un segundo aspecto que la autora destaca se vincula con la concisión que caracteriza a la poesía en lo que concierne a su disposición de elementos:

(...) el texto lírico parecería ostentar en grado máximo una cualidad que si bien es común a todos los textos literarios, se muestra con particular vigor en los textos poéticos: la capacidad de almacenar y transmitir información de modo extremadamente compacto y homogéneo (...) el poema lírico es el espacio que se actualiza en forma exhaustiva una tendencia virtualmente presente en todo texto literario, respecto de la cual la "disposición poética" 
funciona como catalizador: la tendencia a concentrar el mayor volumen de información en la menor superficie textual. (p. 70)

El tercer aspecto que destaca Reisz (1989) es la capacidad de la poesía de trasgredir sus propios márgenes de producción.

La lírica, cualesquiera sean sus variantes — variantes que se derivan de las diferencias entre los esquemas de base transgredidos en cada caso- es fundamentalmente antidiscurso: en ella la sucesividad ordenada del discurso - el alineamiento y la conexión progresiva de los componentes semánticos que se van desplegando a partir de la perspectiva temática unitaria bajo la cual se organiza la acción verbal— se quiebra constantemente como consecuencia del predominio de la tendencia de fuga hacia el no-discurso. (p. 69)

\subsubsection{Definición de poética de autor}

A partir de las reflexiones anteriores relacionadas con la estética posvanguardista y la lírica moderna, la poética de autor se define como un acto de reflexión que, aplicado a la poesía, se encarga de dilucidar el acto creativo del poeta en los terrenos de la lírica, comprendida esta como una experiencia estética y no como la práctica exclusiva de un género literario. Esto supone esclarecer las pautas del reconocimiento de esta práctica.

Primero, se evidencia la necesidad del escritor de incluir, en su reflexión, una mirada teórica (no teorizante) de su proceso creativo (Groys, 2016). Esta reflexión supone, por un lado, alejarse de un intento plenamente interpretativo que lo distancie de su obra, y abrirse al reconocimiento de su producto estético como un acto-objeto (Wajcman, 2001), en el cual las experiencias vitales o estéticas (literarias, plásticas, etc.), materia o insumo de su creación, intervienen en la comprensión de su poética (Rancière, 2011).

Segundo, el escritor contempla la dialéctica entre la potencialidad y la expresión de su acto creativo en el devenir social de su lengua (Agamben, 2016); es decir, sus motivaciones, expectativas y limitaciones en cuanto al uso del lenguaje (estilo). Ello implica reconocer, en sus obras específicas, sus elecciones conscientes (o inconscientes), recogidas de un repertorio 
propuesto por su lengua y por los preceptos que norman las prácticas del paradigma estético bajo el cual escribe o cuestiona (Todorov, 1972).

Tercero, este desarrollo reflexivo le permitirá al escritor potenciar su arte, entenderlo en diferencia con las otras experiencias artísticas (Groys, 2016). Además, logrará verlo como un producto estético indisociable de las tensiones sociales e históricas (Eagleton, 2006).

Cuarto, la lírica, al ser comprendida, más allá del género, como una experiencia estética (Combe, 1999), se configura como un antidiscurso que representa la dinámica de la literatura en sí misma (Merquior, 1999; Reisz, 1989). De igual forma, se emparenta con otros códigos en cuanto a la preminencia de los elementos materiales en la disposición de sus significantes (Reisz, 1989).

Su característica de antidiscurso requiere el ejercicio de una poética de autor que describa lo cambiante y complejo de estas características, que no se centre solo en la arquitectura del texto, y que se encamine hacia el develamiento del proceso creativo integral, el cual incluye las experiencias estético-vitales del creador, habitualmente desdeñadas por la teoría afincada en el texto (Rubio, 1990).

\section{Conclusiones}

$S^{c}$

- Se planteó como objetivo la definición del concepto "poética" a partir de las acepciones que adopta en los estudios literarios (teórica, preceptiva y creativa). Asimismo, al adoptar la acepción creativa, para precisar este concepto, se analizó las convergencias entre la poética y dos tamices de sentido: la estética posvanguardista y la lírica moderna.

- A partir de la relación entre la poética y la estética posvanguardista, se estableció las siguientes ideas guía: (a) el proceso creativo del escritor está encaminado, conscientemente, a la producción de una obra de arte, entendida como un actoobjeto, como una experiencia en sí misma que genera el cambio de visión de mundo del lector a partir de su mismidad; (b) el creador, en el panorama del arte contemporáneo, requiere una explicación teórica de su propio acto de creación con la finalidad de diferenciarse frente a su lector; (c) la poética evidencia necesariamente el trasfondo de lucha ideológica en el panorama social y estético del cual procede la 
obra; (d) el acto de creación configura una tensión que se produce entre la técnica, la voluntad y el estilo; y (e) establecer una poética de autor implica describir, de modo autoreflexivo, la vinculación, en el proceso creativo, de los aspectos técnicos y subjetivos de la creación.

- Acerca de la relación entre poética y lírica moderna, se estableció que la poética es una forma de reflexión del autor acerca de la producción de un texto específico, el poema lírico, el cual encarna un tipo de discurso que excede la categoría de género literario, y presenta cualidades de enunciación y de proceso mimético que tienden al antidiscurso. Frente a su explicación, la poética de autor debe incluir elementos que la poética textual no abarca, de modo especial, las experiencias estético-vitales del creador, las cuales determinan el ordenamiento especial de la lírica, entendida como una experiencia estética.

- Se propuso, finalmente, un concepto de poética de autor, y se delimitó las pautas de reconocimiento que supone esta actividad. 


\section{Referencias}

Agamben, G. (2016). El fuego y el relato. Madrid, España: Sexto Piso.

Bachelard, G. (1997). La poética de la ensoñación. Ciudad de México, México: Fondo de Cultura Económica.

Badía, R. (2017). El lugar de las poéticas explícitas en los estudios literarios. Recuperado de https://digitum.um.es/xmlui/bitstream/10201/51707/1/El\%20lugar\%20de\%20 las\%20poeticas.pdf

Berinstain, H. (1995). Diccionario de retórica y poética. México D.F., México: Porrúa.

Cabo, F. (Comp.). (1999). Teorias sobre la lírica. Madrid, España: Arcos.

Combe, N. (1999). Naturaleza de la lírica. En Cabo, F. (Comp.), Teorías sobre la lírica. Madrid, España: Arcos.

Eagleton, T. (2006). La estética como ideología. Madrid, España: Trotta.

Eco, U. (1993). Lector in Fabula. La cooperación interpretativa en el texto narrativo. Madrid, España: Lumen.

Eco, U. (2000). Las poéticas de Joyce. Barcelona, España: Lumen.

García de la Torre, M. (1983). La prosa didáctica en los siglos de oro. Madrid, España: Playor.

Groys, B. (2015). Volverse público. Las transformaciones del arte en el ágora contemporánea. Buenos Aires, Argentina: Caja Negra.

Groys, B. (2016). Arte en flujo. Ensayos sobre la evanescencia del presente. Buenos Aires, Argentina: Caja Negra.

Hazard, P. (1949). Los libros, los niños y los hombres (Trad. María Manent). Libro digital editado por Smoit. Recuperado de http://www.espaebook.com

Levin, H. (2006). James Joyce. Introducción crítica. México D.F., México: FCE. 


\section{MIGUEL ÁNGEL MALPARTIDA QUISPE}

López Tamés, R. (1990). Introducción a la literatura infantil. Murcia, España: Universidad de Murcia.

Melchiori, G. (1994). Joyce: El oficio de escribir. Madrid, España: Antonio Machado Libros.

Merquior, N. (1999). La referencia desdoblada: El sujeto lírico entre la ficción y la autobiografía. En Cabo, F. (Comp.), Teorías sobre la lírica. Madrid, España: Arcos.

Rancière, J. (2011). El malestar en la estética. Buenos Aires, Argentina: Capital Intelectual.

Reisz, S. (1989). Teoría literaria. Una propuesta. Lima, Perú: PUCP.

Rivas, A. (2005). De la poética a la teoría de la literatura: (una introducción). Salamanca, España: Ediciones Universidad de Salamanca.

Rodari, G. (2004). La imaginación en la literatura infantil. Recuperado de http://www. imaginaria.com.ar/12/5/rodari2.htm

Rubio, P. (1990). Sobre la necesaria integración de las poéticas de autor en la teoría de la literatura. Castilla. Estudios de literatura, (15), 183-197.

Todorov, T., \& Ducrot, O. (1975). Diccionario enciclopédico de las ciencias del lenguaje. México D.F., México: Siglo XXI.

Wajcman, G. (2001). El objeto del siglo. Buenos Aires, Argentina: Amorrortu.

Watanabe, J. (1999). Elogio del refrenamiento. Quehacer, (117). 